\title{
Preventing or Improving Obesity by Addressing Specific Eating Patterns
}

\author{
Jessica L. J. Greenwood, MD, and Joseph B. Stanford, MD, MSPH
}

The problem of obesity and overweight is an epidemic in the United States. Weight is a product of energy balance: energy intake versus energy expenditure. The purpose of this review is to identify adult eating behaviors that are known to strongly affect the energy intake side of the energy balance and that may be readily amenable to prevention and intervention efforts in primary care. Restaurant and fast food consumption, large portion sizes, and consumption of beverages with sugar added increase energy intake and are highly associated with weight gain and obesity. Conversely, consumption of low energy dense food, ie, fruits and vegetables, and routine healthy breakfast consumption can help to maintain or lose weight. These distinct behaviors represent concrete negative and positive eating patterns on which primary care providers can focus when counseling overweight and obese patients. They also represent behavioral targets for designing and testing clinical interventions. ( $\mathrm{J}$ Am Board Fam Med 2008; 21:135-140.)

The problem of overweight and obesity is epidemic in the United States. Body mass index (BMI) $\geq 25$ defines overweight, and BMI $\geq 30$ defines obesity. In 1999 and 2000 the prevalence of overweight and obesity among US adults was $64.5 \%$ and $30.5 \%$, respectively. ${ }^{1}$ Furthermore, from 1960 to 2000, the prevalence of adult obesity increased from $13.4 \%$ to $30.9 \% .{ }^{1}$ Obesity is associated with many chronic diseases including hypertension, type 2 diabetes mellitus, gallbladder disease, coronary heart disease, and hypercholesterolemia. ${ }^{2}$ Therefore, overweight and obesity directly affect these chronic conditions commonly encountered by primary care providers.

Weight is a product of energy balance: energy intake versus energy expenditure. ${ }^{3}$ It is important to address both aspects of energy balance when counseling patients about weight management. A reasonably consistent consensus has been devel-

This article was externally peer reviewed.

Submitted 30 January 2007; revised 3 September 2007; accepted 5 September 2007.

From the Department of Family and Preventive Medicine, University of Utah School of Medicine, Salt Lake City.

Funding: none.

Conflict of interest: none declared.

Corresponding author: Jessica L. J. Greenwood, MD, Department of Family and Preventive Medicine, University of Utah School of Medicine, 375 Chipeta Way, Suite A, Salt Lake City, UT 84108 (Jessica.Greenwood@hsc.utah.edu). oped for counseling patients with regard to energy expenditure. For example, the American College of Sports Medicine, and the United States Department of Agriculture recommend at least 30 minutes of moderate physical activity 4 times a week, ${ }^{4,5}$ whereas the Institute of Medicine recommends 1 hour of moderate physical activity daily for cardiovascular health. ${ }^{6}$ However, similarly simple guidelines do not yet exist for counseling patients on energy intake. The Institute of Medicine and the United States Department of Agriculture have given quantitative guidelines for macronutrient intake. ${ }^{5}$ However, assessing caloric intake can be difficult for patients to conceptualize and for providers to communicate effectively. In contrast, a qualitative approach focused on particular behaviors known to be harmful or beneficial for maintaining healthy weight might be a more effective strategy in clinical settings.

Although energy expenditure is a major contributing factor in the energy balance, this review focuses on specific eating behaviors that are known to affect energy intake, and hence overweight and obesity. The goal of this review is to identify specific concrete behaviors that have well-established associations with overweight and obesity in adults and that may be easily conceptualized, identified, and addressed in a primary care setting. We conducted iterative PubMed searches, starting with the 
keywords diet and obesity. We then expanded the searches from a review of the reference lists and authors of key papers.

\section{Specific Eating Behaviors}

Restaurant/fast food consumption, ${ }^{7-11}$ large portion sizes, ${ }^{12-15}$ and consumption of beverages with sugar added ${ }^{16,17}$ increase energy intake and are associated with overweight and obesity. Conversely, consumption of low energy dense food, ie, fruits and vegetables, decreases energy intake, which can help to maintain or lose weight. ${ }^{18,19}$ Furthermore, routinely eating a healthy breakfast is associated with energy balance and weight control. ${ }^{20-24}$ Each of these behaviors may be readily identifiable in a primary care setting and amenable to clinical counseling or intervention.

Additional behaviors have been found to be associated with overweight and obesity in adults, including nighttime eating, snacking, and alcohol consumption. Night eating is associated with a defined psychiatric disorder, night-eating syndrome (nocturnal hyperphagia, insomnia, and morning anorexia). ${ }^{25-27}$ This makes it less amenable to prevention and intervention in primary care. Snacking between meals is another behavior that has been associated with excessive weight. The overall consumption of snacks in the United States has increased across all age groups; however, this increase has been the greatest in youth ages 2 to 18 years. ${ }^{28}$ Many studies regarding this eating behavior focus on children and adolescents; the foods considered as snacks vary among the different studies and significant cofounders have been identified, including television watching and parental weight. ${ }^{29-31}$ Alcohol consumption has been studied in the context of the metabolic syndrome, which includes central obesity. Varying quantities of alcohol have been associated with lower odds of metabolic syndrome ${ }^{32-35}$; however, the specific association between alcoholic beverages and weight has not been well studied. Therefore, these behaviors have not been included in this review.

\section{Restaurant/Fast Food Consumption}

From 1977 to 1996, the average person $>2$ years old increased restaurant/fast food consumption from $9.6 \%$ to $23.5 \% .^{7}$ During this time period, young adults age 18 to 39 have had the greatest increase in restaurant and fast food con- sumption. ${ }^{7-8,28}$ Restaurant and fast food consumption now represents $32 \%$ of the total calories ingested per person, or one-third of daily total energy. ${ }^{8,9}$ The amount of calories consumed per eating occasion is greater from food prepared away from home as compared with food prepared at home. ${ }^{28}$ Eating restaurant or fast food increases energy intake, and people who consume this food have a significantly higher odds of being overweight compared with those who do not eat fast food (odds ratio, 1.27 and 1.31 , respectively). ${ }^{8}$ There is a positive association between the frequency of eating restaurant or fast food and increases in body weight. Pereira et $\mathrm{al}^{9}$ found that over a 5 -year period, eating fast food 3 times per week is associated with $1.6 \mathrm{~kg}$ to $2.2 \mathrm{~kg}$ weight increase $(P<.01)$. Furthermore, analysis of state-level data indicates that the number of residents in a region per fast food restaurant correlates with the prevalence of obesity $(\mathrm{r}=0.53 ; P<.001) .{ }^{10}$ Thus, multiple lines of evidence indicate that frequency of eating restaurant or fast food is associated with positive energy balance and excessive weight.

The studies above do not distinguish between restaurant food and fast food. Duffey et $\mathrm{al}^{11}$ find this to be a limitation in previous studies of this behavior. Their findings from a longitudinal study indicate significant increases in BMI with fast food consumption over time, but not with restaurant food consumption. Duffey et al found a 0.13-unit increase in BMI at 7 years with each unit (1 time/ wk) increase in fast food consumption $(P=.003)$, and this increase in $\mathrm{BMI}$ was sustained at 10 years $(P=.001)$. Conversely, longitudinal increases in restaurant food consumption resulted in minimal, but not significant, decreases in $\mathrm{BMI}(P=.756$ at 7 years, $P=.676$ at 10 years). ${ }^{11}$

\section{Large Portion Size}

Portion size is closely related to restaurant and fast food consumption; the largest food portions in the United States come from restaurants and fast food establishments. ${ }^{36}$ Between 1977 and 1996, portion sizes and energy intake increased in the US population older than 2 years of age when considering home, restaurant, and fast food sources. ${ }^{36}$ The greater the amount of food presented to people, the more food is consumed. ${ }^{12-15}$ Levitsky and Youn ${ }^{12}$ revealed that energy intake significantly increases when people are offered $125 \%$ and $150 \%$ of a control portion of food $(P<.05)$. Similarly, people 
eat $43 \%$ more energy (172 kcal) when $150 \%$ portion size is offered from a restaurant. ${ }^{14}$ Likewise, people consume $30 \%$ more food and energy when presented with a $1000-\mathrm{g}$ portion of food as compared with a $500-\mathrm{g}$ portion. A $1000 \mathrm{~g}$ portion is consistent with a typical restaurant size portion. ${ }^{13}$ When portions increase $50 \%$ and $100 \%$ above baseline, energy intake increases an average of $120 \%$ and $130 \%$ above energy needs, respectively. ${ }^{15}$ Therefore, large portion sizes, as are frequently served in restaurants and fast food establishments, directly increase energy intake, which can lead to excessive weight.

\section{Beverages with Sugar Added}

Beverages with sugar added, a combination of soft drinks and fruit drinks, contribute over $40 \%$ of sugar added to the average diet in the United States. $^{37,38}$ Between 1977 and 1996, the overall sugar-added drink consumption increased significantly, from $3.1 \%$ to $6.1 \%$ with meals and $10.3 \%$ to $11.6 \%$ with snacks. ${ }^{28}$ Also during this time, the average energy consumed from soft drinks increased from $144 \mathrm{kcal}$ to $193 \mathrm{kcal}{ }^{36}$ Approximately $2 \mathrm{~g}$ of sugar-added beverages per kilogram of body weight has been associated with significant increases in energy intake $(1.5 \mathrm{~mJ} /$ day $)$, body weight $(1.6 \mathrm{~kg})$, and fat mass $(1.3 \mathrm{~kg})$ in adults over a 10 -week period $(P<.05) .{ }^{16}$ Similarly, studies show that adolescents who increase intake of the amount of sugar-added beverages increase total energy intake and gain weight. ${ }^{17}$ Over a period of 1 year, boys who drank 1 or 2 sugar-added beverages a day significantly increased their BMI by $0.10(P=.02)$ and $0.14(P=.01)$, respectively ${ }^{17}$; girls who drank 2 or more sugar-added beverages a day also significantly increased their BMI by $0.10(P=.046) .{ }^{17}$

\section{Fruits and Vegetables}

Energy density is a measure of energy content per weight of food..$^{39}$ Foods with low energy density tend to have a high water and fiber content, such as fruits and vegetables, whereas high energy dense foods tend to have a high fat content. ${ }^{18}$ The intake of high energy dense foods results in greater energy intake than the intake of an equal weight of low energy density food. Bell and Rolls ${ }^{19}$ showed that women consume $20 \%$ less daily energy (a 450-kcal reduction) when they consume a diet with low energy density food as compared with high energy dense food $(P<.001)$. Similarly, a $25 \%$ reduction in overall food density was found to result in a $24 \%$ reduction of energy intake $(P<.0001) .{ }^{40}$ According to Bell et $\mathrm{al}^{41}{ }^{41}$ when comparing high, medium, and low energy dense diets, one would have to eat $30 \%$ more of a low energy dense diet and $12 \%$ more of a medium energy dense diet to equal the energy intake of a high energy dense diet. Similarly, compared with people eating high dense foods, men who consume low energy dense foods can decrease total energy intake by $432 \mathrm{kal} / \mathrm{d}$ and women by $278 \mathrm{kcal} / \mathrm{d} .^{42}$ Increases in energy intake associated with higher energy dense foods do not seem to be compensated for by increased energy expenditure, thus resulting in a positive energy balance. ${ }^{43}$ Consumption of energy dense foods with high fat content positively correlates with increased energy intake. ${ }^{43,44}$ However, this is not an issue only of fat intake because high energy dense food consumption increases energy intake independently of portion size and fat content. ${ }^{44,45}$

For the reference 2000 calorie diet, the US Department of Agriculture recommends at least 4 1/2 cups, or 9 servings, of fruits and vegetables daily for health maintenance. ${ }^{4}$ Daily caloric need is based on age, sex, and activity level. The reference 2000 calorie diet is based on the caloric needs of a sedentary adult, one who only achieves light physical activity associated with typical daily activities. ${ }^{3}$ Middle-aged women who eat 1.9 servings of fruits daily have a $25 \%$ lower risk of obesity (odds ratio, $0.75 ; P<.001)$ compared with women who eat fewer servings. ${ }^{46}$ Similarly, women who eat 2.8 servings of vegetables have a significantly lower risk of weight gain (odd ratio, $0.84 ; P<.0001$ ) compared with those who eat fewer servings. ${ }^{47}$

\section{Breakfast Consumption}

Twenty percent to $30 \%$ of the adult US population does not eat breakfast. ${ }^{21}$ After adjusting for confounding factors, those who do not eat breakfast have a significantly higher BMI than those who eat cereal or bread for breakfast $(P<.01) .{ }^{48}$ Those who skip breakfast have 4.5 times increased odds (95\% CI, 1.6-12.9) for obesity compared with those who eat breakfast regularly ( $>75 \%$ of days). ${ }^{48}$ Similarly, obesity is also associated with skipping breakfast 4 or more times weekly (odds ratio, 1.98; $P<.05) .{ }^{23}$ Furthermore, there may be advantages to eating breakfast in the context of attempting to lose weight. ${ }^{24}$ 
The exact mechanism of breakfast consumption and improved weight management is unknown. It has been shown that the number of eating episodes is inversely associated with the risk of obesity. Those who eat 4 or more times daily have a $45 \%$ lower risk of obesity compared with those who eat $<4$ times a day. ${ }^{48}$ Paradoxically, studies show that the total energy intake can be greater in those who eat breakfast. ${ }^{48,49}$ Whether it is the effect of consumption frequency on metabolism, decreased energy intake throughout the rest of the day, or greater health consciousness in terms of energy balance has not been determined. ${ }^{24,49}$ However, the overall nutritional benefits of breakfast consumption outweigh the risks. ${ }^{21}$

Particular characteristics of breakfast foods and consumption are important. It may be that ensuring adequate time to eat breakfast (approximately $\geq 20 \mathrm{~min})$, is important $(P<.05) .{ }^{24}$ Importantly, eating breakfast at home is beneficial and significant because eating out can double the risk of obesity compared with eating breakfast at home. ${ }^{48}$ Eating a substantial breakfast (approximately 20\% of total daily energy intake) is inversely related to obesity $(\mathrm{r}=0.3281 ; P<.05) .{ }^{24}$ Some researchers suggest that breakfast should be less than $25 \%$ of total daily energy intake and that a high energy breakfast with large amounts of protein, fat, and carbohydrates is not better than a low energy breakfast. ${ }^{50}$ Specifically, eating only dairy, meat, and/or egg food groups can be just as detrimental as skipping breakfast. ${ }^{21}$ Conversely, consumption of a low energy breakfast bread or cereal is associated with normal weight, lower BMI, and lower energy intake..$^{20,23,24,49-51}$

\section{Conclusion}

Consumption of restaurant and fast food, large portion sizes, and sugar-added beverages increase energy intake, creating a positive energy balance. These behaviors are positively associated with overweight and obesity. Conversely, fruit and vegetable consumption and healthy breakfast consumption are negatively associated with overweight and obesity. These specific behaviors may be amenable to clinic-based counseling in identifying behaviors that put people at high risk for becoming overweight or obese. In a primary care setting, addressing these specific behaviors may be more feasible than efforts to assess and modify global caloric intake.
To our knowledge, using targeted assessments or counseling messages regarding these behaviors has not yet been tested in a primary care setting. Future research is necessary to screen for these particular eating behaviors and to develop effective education resources for the use of patients and providers. Meanwhile, these behaviors form a relevant and pertinent focus for brief dietary advice to patients that is easy to discuss and comprehend and that is supported by currently available research.

\section{References}

1. Flegal K, Carroll M, Ogden C, Johnson C. Prevalence and trends in obesity among US adults, 19992000. JAMA 2002;14:1723-7.

2. Must A, Spadano J, Coakley E, Field AE, Colditz G, Dietz WH. The disease burden associated with overweight and obesity. JAMA 1999;16:1523-29.

3. Hill JO, Wyatt HR, Melanson EL. Genetic and environmental contributions to obesity. Med Clin North Am 2000;84:333-46.

4. US Department of Health and Human Services. Dietary guidelines for Americans, 2005. Available at http://www.health.gov/dietaryguidelines/dga2005/ document. Accessed 16 January 2008.

5. How much exercise is enough: responding to the IOM report on dietary guidelines. Sports Med Bulletin 2002: 37; 5. Available from: http://www.acsm.org/AM/ Template.cfm? Section $=$ Search\&section $=20021 \&$ template $=/ \mathrm{CM} /$ ContentDisplay.cfm $\&$ ContentFileID $=$ 345 .

6. The National Academies. Dietary reference intakes for energy, carbohydrate, fiber, fat, fatty acids, cholesterol, protein, and amino acids. 2002. Available at http://www.iom.edu/CMS/3788/ 4576/4340.aspx? printfriendly $=$ true. Accessed 16 January 2008.

7. Guthrie JE, Hwan B, Frazao E. Role of food prepared away from home in the American diet, 1977-78 versus 1994-96: changes and consequences. J Nutr Edu Behav 2002;34:440-50.

8. Bowman SA, Vinyard BT. Fast food consumption of US adults: impact on energy and nutrient intakes and overweight status. J Am Coll Nutr 2004;23:163-8.

9. Pereira MA, Kartashov AI, Ebbeling CB, et al. Fastfood habits, weight gain, and insulin resistance (the CARDIA study):15-year prospective analysis. Lancet 2005;365:36-42.

10. Maddock J. The relationship between obesity and the prevalence of fast food restaurants: state-level analysis. Am J Health Promot 2004;19:137-43.

11. Duffey KJ, Gordon-Larsen P, Jacobs DR Jr, Williams OD, Popkin BM. Differential associations of fast food and restaurant food consumption with $3-y$ change in body mass index: the coronary artery risk 
development in young adults study. Am J clin Nutr 2007;85:201-8.

12. Levitsky DA, Youn T. The more food young adults are served, the more they overeat. J Nutr 2004;134: 2546-9.

13. Rolls BJ, Morris EL, Roe LS. Portion size of food affects energy intake in normal-weight and overweight men and women. Am J Clin Nur 2002;76: 1207-13.

14. Diliberti N, Bordi PL, Conklin MT, Roe LS, Rolls BJ. Increased portion size leads to increased energy intake in a restaurant meal. Obes Res 2004;12:562-8.

15. Rolls B, Roe L, Meengs J. Larger portion sizes lead to a sustained increase in energy intake over 2 days. J Am Diet Assoc 2006;106:543-9.

16. Raben A, Vasilaras TH, Moler AC, Astup A. Sucrose compared with artificial sweeteners: different effects on ad libitum food intake and body weight after 10 wk of supplementation in overweight subjects. Am J Clin Nutr 2002;75:721-9.

17. Berkey CS, Rockett HRH, Field AE, Gillman MW, Colditz GA. Sugar-added beverage and adolescent weight change. Obes Res 2004;12:778-88.

18. Rolls BJ, Drenwnoswski A, Ledikwe JH. Changing the energy density of the diet as a strategy for weight management. J Am Diet Assoc 2005;105:98-103.

19. Bell EA, Rolls BJ. Energy density of foods affects energy intake across multiple levels of fat content in lean and obese women. Am J Clin Nutr 2001;73: 1010-8.

20. Morgan KJ, Zabik ME, Stampley GL. The role of breakfast in diet adequacy of the U.S. adult population. J Am Coll Nutr 1986;5:551-63.

21. Cho S, Dietrich M, Brown CJP, Clark CA, Block G. The effect of breakfast type on total daily energy intake and body mass index: results from the third national health and nutrition examination survey. J Am Coll Nutr 2003;22:296-302.

22. Keski-Rahkonen A, Kaprio J, Rissanen A, Virkkunen M, Rose RJ. Breakfast skipping and health-compromising behaviors in adolescents and adults. Eur J Clin Nutr 2003;57:842-53.

23. Schlundt DG, Hill JO, Sbrocco T, Pope-Cordle J, Sharp T. The role of breakfast in the treatment of obesity: a randomized clinical trial. Am J Clin Nutr 1992;55:645-51.

24. Ortega RM, Redondo R, Lopez-Sobaler AM, et al. Associations between obesity, breakfast-time food habits and intake of energy and nutrients in a group of elderly Madrid residents. J Am Coll Nutr 1996; 15:65-72.

25. Andersen GS, Stunkard AJ, Sorensen TIA, Petersen L, Heitmann BL. Night eating and weight change in middle-aged men and women. Int J Obes 2004;28: $1338-43$.

26. Gluck ME, Geliebeter A, Satov T. Night eating syndrome is associated with depression, low self- esteem, reduced daytime hunger, and less weight loss in obese outpatients. Obes Res 2001;9:264-7.

27. Stunkard AJ, Grace WJ, Wolff HG. The nighteating syndrome: a pattern of food intake among certain obese patients. Am J Med 1955;78-86.

28. Nielsen SJ, Siega-riz AM, Popkin BM. Trends in energy intake in U.S. between 1977 and 1996: similar shifts seen across age groups. Obes Res 2002;10: 370-8.

29. Field AE, Austin SB, Gillman MW, et al. Snack food intake does not predict weight change among children and adolescets. Int J Obes 2004;28:1210-6.

30. Phillips SM, Bandini LG, Naumova EN, et al. Energy-dense snack food intake in adolescence: longitudinal relation ship to weight and fatness. Obes Res 2004;12:461-72.

31. Francis LA, Lee Y, Birch LL. Parental weight status and girls' television viewing, snacking, and body mass indexes. Obes Res 2003;11:143-51.

32. Freiberg MS, Wasan RS, Cabral HJ, Ellison RC, Heeren TC. Alcohol consumption and the prevalence of the metabolic syndrome in the U.S. Diabetes Care 2004;27:2954-9.

33. Djousse L, Arnett DK, Eckfeldt JH, Province MA, Singer MR, Ellison RC. Alcohol consumption and the metabolic syndrome: does the type of beverage matter? Obes Res 2004;12:1375-85.

34. Rosell M, De Raire U, Hellenius ML. Low prevalence of the metabolic syndrome in wine drinkers is it the alcohol beverage or the lifestyle? Eur J Clin Nutr 2003;57:227-34.

35. Zhu S, St-Onge MP, Heshka S, Heymsfield SB. Lifestyle behaviors associated with lower risk of having the metabolic syndrome. Metabolism 2004;53: 1503-11.

36. Nielsen SJ, Popkin BM. Patterns and trends in food portion sizes, 1977-1998. JAMA 2003;289:450-3.

37. Guthrie JF, Morton JF. Food sources of added sweeteners in the diets of Americans. J Am Diet Assoc 2000;100:43-51.

38. Johnson RK, Frary C. Choose beverages and foods to moderate you intake of sugars: the 2000 dietary guidelines for Americans what's all the fuss about? J Nutr 2001;131:2766S-71S.

39. Rennie KL, Johnson L, Jebb SA. Behavioral determinants of obesity. Best Pract Res Clin Endocrinol Metab 2005;19:343-58.

40. Rolls BJ, Roe LS, Meengs JS. Reductions in portion size and energy density of foods are additive and lead to sustained decreases in energy intake. Am J Clin Nutr 2006;83:11-7.

41. Bell EA, Castellanos VH, Pelkman LC, Thorwart ML, Rolls BJ. Energy density of foods affects energy intake in normal-weight women. Am J Clin Nutr 1998;67:412-20.

42. Ledikwe JH, Blanck HM, Khan LK, et al. Dietary energy density is associated with energy intake and 
weight status in US adults. Am J Clin Nutr 2006;83: 1362-8.

43. Stubbs RJ, Ritz P, Coward WA, Prentice AM. Covert manipulation of the ratio of dietary fat to carbohydrate and energy density: effect on food intake and energy balance in free-living men eating ad libitum. Am J Clin Nutr 1995;62:330-7.

44. Kral TVE, Iane RS, Rolls BJ. Combined effects of energy density and portion size on energy intake in women. Am J Clin Nutr 2004;79:962-8.

45 Rolls BJ, Bell EA, Castellanos VH, Chow M, Pelkman CL, Thorwart ML. Energy density but not fat content of foods affected energy intake in lean and obese women. Am J Clin Nutr 1999;69:863-71.

46. He K, Hu F, Colditz G, Manson J, Willett W, Liu S. Changes in intake of fruits and vegetables in relation to risk of obesity and weight gain among middleaged women. Int J Obes 2004;28:1569-74.

47. Rolls BJ, Row LS, Meengs JS. Salad and satiety: energy density and portion size of first-course salad affect energy intake at lunch. J Am Diet Assoc 2004; 104:1570-6.

48. Ma Y, Bertone ER, Stanek EJ, et al. Association between eating patterns and obesity in a free-living US adult population. Am J Epidemiol 2003;158:8592.

49. Adams CE, Morgan KJ. Periodicity of eating: implications for human food consumption. Nutr Res 1981;1:525-50.

50. Martin A, Normand S, Sothier M, Peyrat J, LouchePelissier C, Laville M. Is advice for breakfast consumption justified? Results from a short-term dietary and metabolic experiment in young healthy men. Br J Nutr 2000;84:337-44.

51. Barton BA, Eldridge AL, Thompson D, et al. The relationship of breakfast and cereal consumption to nutrient intake and body mass index: the national heart, lung and blood institute growth and health study. J Am Diet Assoc 2005;105:1383-9. 